Covered in: ERIH PLUS, CEEOL, Index Copernicus, CrossRef, CrossCheck, J-Gate, Google Scholar, Ideas RePeC, Econpapers, Socionet, KVK, WorldCat.

\section{Nikos Kazantzakis's Writing Style in the Original and Translation}

\section{Tinatin DARAKHVELIDZE 1}

${ }^{1} \mathrm{PhD}$. Candidate, The Saint Andrew The First Called Georgian University, Tbilisi, Georgia

\begin{abstract}
The article deals with Nikos Kazantzakis's creative style, and how, in what ways and to what extent the writer's style is adequately reflected in the translation. The factors that determine Kazandzakis' creative style are outlined, in particular a few key points from his biography, which has led to the development of a writer 's outlook and writing habits, without which it is difficult to ascertain the true meaning of translation. Based on the contrasting analysis of Nikos Kazantzakis's novel "Zorba the Greek" and his Georgian translation, we tried to find out how the translator adequately understands the nuances of the original ethnical consciousness, which is one of the characteristics of the Kazantzakis's style and how properly the translator managed to translate them. Nikos Kazantzakis's language is always interesting for researchers and it provides them with various material. The writer's special approach to language is evident in all his works, except for the abundance of his native Cretan dialect, the writer abundantly uses his own fictional neologisms in his works, complicating the process of translator's work. Ethno-linguistic specifics such as dialect expressions and neologisms clearly show the specifics of ethnical mentality. In order to understand ethnical consciousness and mentality properly and to translate it further, it is necessary to take realies and the background knowledge into account. In the present article we will try to analyze if the translator takes all of these components into account in order to obtain an adequate translation.
\end{abstract}

Keywords: translation; writer; language; Crete; Greek language.

How to cite: Darakhvelidze, T. (2019). Nikos Kazantzakis's Writing Style in the Original and Translation. Logos Universality Mentality Education Novelty: Philosophy \& Humanistic Sciences, 7(2), 15-31. doi: 10.18662/lumenphs/24 


\section{Introduction}

The spesifics of the critical analyses of fiction translation are based on its ambivalent nature as it also expresses the characteristics of the original text and the culture of the nations who speak this language at the same time with the help of other linguistic means. Therefore fiction translation is valued by the degree of merging of foreign and native cultures. The synthesis of foreign and native cultures will be of higher quality, the more harmonious their elements will be combined (Panjikidze 1999: 37). 1. Translation should be done as accurately as possible not only the content of the original but also the fictional side, that is, the unity of form and content must be preserved in translation; 2 . The translation must be reflected with a trace of an era; 3. The synthesis of foreign and native cultures must be reflected in translation; 4. Translation should take its readrs into account, but it must raise the level of its reader and broaden a reader's outlook, i.e. a translator should also take on the mission of the cultural trader (Panjikidze 1999: 37).

Kazantzakis' innovative creative thinking, his most complicated word formation had already attracted the scholars' attention. If there is a difficult and easily translated literature, Kazanzakis must be undoubtedly belonged to the difficult translating category. One of the major difficulties for a translator is the very original and symbolized forms of expressions and the determination of their fate in translation.

The writer's style of creating his heroes/heroins complicates the ability to translate. All of this requires the translator not only to be thoroughly knowledgeable in the original text and in its detailed understanding, but it also demands to be as free and easy as Kazantzakis has revealed.

The present study deals with Nikos Kazantzakis's writing style and how, in what ways and to what extent the writer's style is adequately reflected in translations. Kazantzakisi's creation is translated into many languages. The reserchers of his writings confirm that it is impossible to translate them perfectly, as the writer's language is rich in the author's own neologisms and Cretan and other Greek dialects. While translating Kazantzakis' works, the translator is not only sufficient to know Greek, he/she must also know the history of Greek language development, the nuances of Greek dialects, as well as the details of the writer's biography and creation. We will try to define Kazantzakis's style and the difficulties of translating his writings. 


\section{Main Part}

The present study deals with Nikos Kazantzakis's writing style and how, in what ways and to what extent the writer's style is adequately reflected in translations. It is important to identify the factors that determine the creative style of Kazantzakis, without which it is difficult to find out the true meaning of the translation. Buffon's chrestomathical definition - "Style is a Man" - is relevant to Kazantzakis too, so we will utilize from his creative biography the facts which, in our opinion, had an influence on his writing style and of course they were taken into account by the translator while translating them. The writer's biography starts with the island of Crete where he was born on the $18^{\text {th }}$ of February, in 1883. That time the island of Crete was still under the rule of the Ottoman Empire, that's why the Kazantzakis's family escaped from the island twice,-first, they went to Pireasi in 1889 and secondly they went to the island of Naxos in 1897-98. While living on Naxos, he continued learning at Roman-Catholic school, where he studied French and Italian. The knowledge of these languages played a major role in his later life. After graduating from the faculty of law at the University of Athene, he went on his studying in Paris, at the faculty of Philosophy at the Sorbonne. There he fell under the influence of the French philosopher Henri Bergson who greately influenced on the writer. In addition to Bergson, Friedrich Nietzsche's deep influence can also be felt on Kazantzakis's creation. His doctoral dissertation as in Athene as in Paris was dedicated to Friedrich Nietzsche "Friedrich Nietzsche dans la philosophie du droit et de la cité („Friedrich Nietzche about Law and Philosophy of State"). This influence must have been one of the reasons as upon his return to Greece,he began translating works of philosophy. Nikos Kazandzakis's biography is readily followed by travells. It was like he was taking spiritual nourishment from his travels, collecting impressions like a valuable treasure and then bringing everything he had seen and felt onto the sheet. Impressions of his travels, which have been published throughout the series, is read just as interestingly as novels. The writer, along with his friend Angelos Sikelianos, traveled for two years to the areas where Greek Orthodox Christian culture was on the rise. Kazantzakis's Cretan origin, his love towards his home-country played a great role in formation of the writer's style. The researchers of Kazantzakis' creations agree that Nikos Kazantzakis was an unbelievable fluent in Greek, having known all stages of Greek language development from Homeros to Modern Greek. His love of Greek dialects is also worthy noting. He makes great emphasis on the Cretan dialect in his works, but the writer uses not only the 
Cretan dialect, but also other Greek dialects. Therefore, while translating his texts, it is notable to take the diversity of Greek dialects into account, in order to understand the context better, not to lose the colouring of the text and the author's individual manner of narration. Noteworthy is the author's dictionary of the first edition of his poem "Odyssey", in which the author defines more than 1,500 words used in the poem. Kazantzakis himself writes in the preface of this dictionary: "The most difficult words which are taken from different parts of Greece are definied and included after many years selection in this dictionary, in this creation." It is not indicated which dialect the word belongs to in this dictionary but there is no doubt that the elements of the Cretan dialect predominate in his works. His characters come from Cretan entrails, their speech and environment are saturated and described by the strokes of the Cretan dialect and there a question arises: how much of the Cretan elements are preserved in Kazantzakis's works translated into many languages? Does the Cretan's character and identity which are seen by the Cretan writer reach to readers while the Cretan dialects and idioms are behind? As we have already noted, Kazantzakis's creation is rich in dialects which are expressed by lexis, phonetics and grammer. There are local lexical elements in the characters' speech which naturally carry their stylistic function. With the help of the characters' speech, the writer presents the local colouring, the characters' social belonging, the level and nature of their culture. The researchers of Kazantzakis's creation point to the special role of dialecticism in its texts as at phonetic-morphological, as at the lexical level. Dialecticisms in fiction are used as: a)Basic linguistic means i.e. the deviation from the literary norm is characteristic for the whole work, both for the author and for the characters' speech; b) Linguistic characterization of individual characters; c) Exoticism, to create some colouring. In the case of Kazantzakis it can be said that dialectisms are not the main linguistic means of the work, but they are the means of linguistic characterization of characters and the means of creating a certain colouring. Greek readers are given the opportunity to discover the pearls of the Cretan dialect and the forgotten words which the writer had been collecting all his life in order to use them in his writings. Cretan and not only Cretan dialect vocabulary is lost in translation and of course, a reader cannot perceive the richness of the writer's language. Phonetic peculiarities of the characters' speech are entirely lost in the translated texts as they are expressed by the literary language lexis. By losing phonetic features in the translated text, it loses its specific tone, which is created with the help of using dialectisms in the original. The examples of lexicographic dialectisms are such words which are only characteristic for those concrete 
nation's speech. The Cretan lexis is translated into common literary language with the appropriate equivalents or other lexical means that express their meaning according to the context.

Another important factor in Kazantzakis' creative style is the author's neologisms. The writer uses his own words in his writings, which complicates not only the translation process but also reading of the original, as such words are not found in any dictionary. As a rule, new words are invented by writers and created to emphasize the individual characteristics of their style. The author uses neologisms to reinforce the emotional expressiveness of the text. The author's neologisms are the words which are created by the writer to depict reality or fictional events and objects. The author's newly invented words differ from ordinary words in their internal structure or combination of different elements. Three types of neologisms are known:

1. 1. Semantic Derivation - Creating a new, secondary meaning from an already existing word. By bringing a new meaning and proximity to existing ones.

2. Word formation derivation - creation of new words by means of morphemes known in the language, i.e words that already exist in the language. Such neologisms are mainly created by prefix-suffix.

3. Derivation according to the words of other language, such as: talk show, sponsor, selfie and etc.

Literary neologisms, imaginative composite and linguistic words, a marriage of folk words with unique skill, established Kazantzakis as a unique punter of modern literature. From the great poetic work of the great writer we stylized some of these linguistic diamonds:

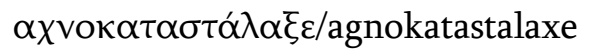

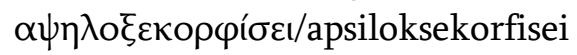

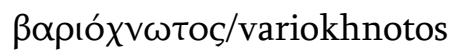

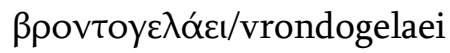

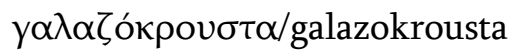

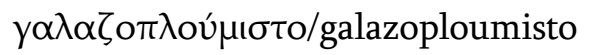
$\gamma \iota \alpha \lambda \circ \xi \varepsilon \varphi \alpha \vee \tau \omega ́ \sigma o u v / g i a l o k s e f a n d o s o u n$ $\gamma \lambda \cup \kappa \alpha \vee \tau \iota \varphi \varepsilon ́ \gamma \gamma ı \zeta \alpha v /$ glikantigengizan

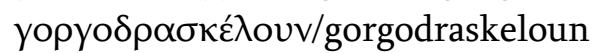

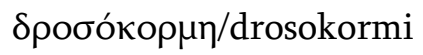
$\varepsilon \rho \omega \tau o ́ \lambda \alpha \mu v \eta /$ erotolamni $\theta \alpha \lambda \alpha \sigma \sigma o ́ \varphi \rho v \delta o /$ thalasofrido 
$\theta \alpha \mu \pi \alpha \dot{\chi v} \backslash \zeta \varepsilon /$ thambakhnize $\kappa \varepsilon \varphi \alpha \lambda o ́ \delta \varepsilon \sigma \varepsilon \varsigma /$ kefalodeses

$\kappa \lambda \omega \theta \alpha v \eta \varphi о \rho i \zeta o u v / k l o t h a n i f o r i z o u n$

корчо $\lambda i ́ \mu \alpha v o /$ korfolimano

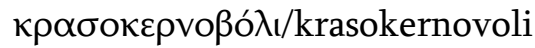

$\mu \alpha \nu \rho \circ \mu \alpha v \tau \imath \lambda \omega \theta \varepsilon i ́ \tau \varepsilon / m a v r o m e n d i l o t h i t e$

$\mu \varepsilon \lambda o ́ \chi \rho o v \sigma \alpha /$ meloxrousa

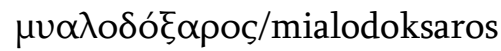

$\mu v \alpha \lambda \circ \zeta v \gamma ı \alpha ́ \zeta \varepsilon /$ mialoligizei

$\mu \nu \rho ı \xi о \mu \pi \lambda \lambda_{\iota} \alpha \sigma \omega /$ mirioksompliaso

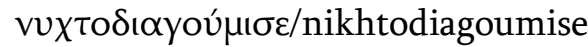

vvхтото́ $\rho \omega \rho о \varsigma /$ nikhtoparoros

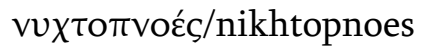

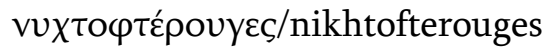

$\xi \varepsilon \theta \rho \alpha ́ \alpha \sigma \varepsilon \psi \varepsilon /$ ksethrasepse

$\xi \varepsilon \mu \alpha \rho \gamma \omega ́ v o u v /$ ksemargonoun

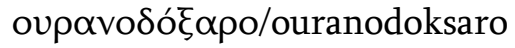

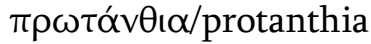

$\pi \rho \omega \tau \alpha \varphi \rho \alpha ́ \tau o / p r o t a f r a t o$

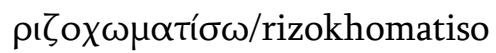

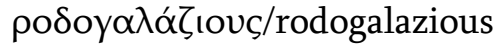

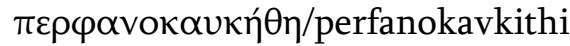

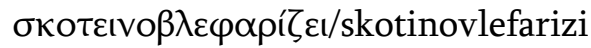

$\sigma u ́ \varphi \lambda$ oy $\alpha /$ sifloga

$\tau \rho \alpha \gamma o u \delta o \mu o t \rho o \lambda o ́ / / t r a g o u d o m i r o l o i$

$\varphi \varepsilon \gamma \gamma \alpha \rho \circ \sigma \tau \alpha \dot{\zeta}$ ovv/fengarostazoun

$\varphi$ ıо́корн $\alpha /$ fidokorma

$\chi \alpha \mu о \beta \lambda \varepsilon \varphi \alpha \rho i ́ \sigma \alpha v /$ khamovlefarisan

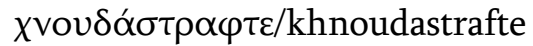

$\chi \rho \circ v \sigma o \xi o ́ \mu \pi \lambda_{\iota} \alpha \sigma \tau /$ xrousoksomliasto

The first step of translating an author's neologisms and translating of neologisms, in general, is to make sure that the specific lexical element is really a neologism. The mere fact that a particular word is not mentioned in the dictionary, cannot be a reason for this word to be automatically considered as a neologism, since that particular word may not be mechanically omitted in the dictionary or the dictionary has not been 
updated. Therefore, when translating, it is recommended to use the latest dictionaries. There is a classifier created by a French scientist Cabré (1999) that helps us in identifying and defining neologisms: definition of the psychological, lexicographic, diachronic and also lexical unit itself that bears formal signs of this semantic instability.

The second stage of translation of neologism involves a translator's definition of the meaning of neologism based on recent editions, which explains the meaning of the new word in terms of its structure and context. The third stage is to properly translate (transmit) the target language. In addition to author's neologisms, Kazantzakis uses such neologisms which are the result of relations between languages and peoples. Such neologisms are for example, lexical units from the Turkish language. In the case of the Turkish language, a forced or voluntary historical relationship has become a fact of the past, but the lexical units of this foreign language have taken their place in the Greek language. The introduction of terms (and not just theirs) into the language has become intense and there is a tendency to enter and establish these vocabulary units unchanged. Thus, a vocabulary composition of a certain language is variable, with the development of life, the vocabulary of the language lacking words which relevant objects or events have become part of history, in return the words and expressions characteristic of the new being are taking place. The development of language is primarily reflected on its vocabulary. Lexical units take place in the language system in various ways and become indigenous. By its very nature, neologism is a phenomenon without a generalized law. There are several inaccuracies in translating of such neologisms.

Translating is a complicated process. In order to translate an original thought correctly and accurately, it is necessary not only to find the right words in the target language, but also to put them in the appropriate grammatical form. This is still often the case with stylistic factors that cannot be ignored by translation to express something completely in one language in one way which has been already expressed in the other language (Fedorov, 1983). The study of the process provides an empirical basis for contrasting, typological and cross-cultural studies and allows us to observe the interplay of ethnic consciousness. Selection of the cultural-fictional text, as the object of research, has significantly determined by its multifunctionality and individuality. It does not fall into any one functional type and in most cases contains fragments of different functional styles. Fiction, unlike science fiction, allows for the intercultural communication modeled on fictional forms to be traced directly, giving highly interesting empirical material. Among the works that provide such an opportunity, both 
in fictional-aesthetic and informative terms, is Nikos Kazandzakis's 'Zorba the Greek".This novel reveals the awareness of people of different cultures and ethnicities. They have their own view of the world and events, which in many cases do not coincide with the position of those around them. The writer portrays the wrestling of consciousness, the attempts to complicate and harmonize interpersonal and social relationships, the specifics and dynamics of which are always determined by the appropriate culture. In addition to the "Zorba the Greek" being an interesting empirical material for the present study, our interest in Kazantzakis has been determined by several factors: a) The cultural polyphony of the characters in the novel, which allows us to observe the people interacting with different mentalities and values; b) The linguopersonal specifics of the writer, who found expression in the distinctiveness and peculiarity of his style. The content of this fictional text, its types and characters, its style, which means the selection and proper organization of linguistic conditions, is conditioned by the ideological-artistic positions of the writer. Therefore, one of the foremost roles in the style of translating a writer's prose is to determine the position of the writer, his attitude to the reality, events and characters depicted in the work of fiction. At the same time, within one work, hatred or sympathy for particular events and characters may be expressed, and the whole work may have a distinct position that creates a general atmosphere of the novel and defines the aesthetic and cognitive values of the work as a whole. According to D.Panjikidze, ,"The writer 's fictional position, in turn, is shaped by his outlook, literary traditions, literary influences, epochal shifts in the writer' $\mathrm{s}$ homeland and in the modern world, the general level of world science and culture and so on" (Panjikidze 1988: 80-81). As the translation analysis assures us, Kazantzakis's translator partly takes these requirements into account. Despite the great importance attached to the national-cultural specifics of the original, the problem of the author's individual style and aesthetics still remains to be determined, which as noted above, reveals both in ideological-artistic design and in the linguistic material pursued for its implementation. The need of orientation towards foreign readers leads to the necessity of some adaptation, which is, in some cases, related to the substitution of one or more means of expression in the appropriate form of the literary tradition of the target culture. The main difficulty for the translator is the variety, as he/she is given the freedom to find and choose a stylistic way in which his/her taste and style are revealed. A translator must not only deeply understand the aesthetics of the author, his thoughts and ways of expressing them, but also he/she must turn a literary work into as if it is his/her own one. A translator does not attempt 
to "subordinate" his / her creative individuality to the author, and in fact, there is, at best, literary editing in which the writer's individuality is completely erased and the writer and his characters begin to speak in the translator's language. In order a reader to see the face of the author, the translator has to find not formal but functional equivalence for the author's methods which implies not being aside, but an active creative position. A perfect translation can't be done without a translator's private life and creative experience. Creating a perfect translation depends on the translator's ability to be transformed according to the author's aesthetic system and style. The translator, as well as the actor, must be capable of adaptation and, despite personal antipathy, must be able to convey the author's opinion and style to the addressee. Based on the above considerations, we will try to analyze the problem of coincidence between the copyright style of Kazantzakis and the translator's style of translation. The problem faced by the translator is the preservation of the foreign colouring, the ambivalent nature of the translation, that the translation combines two things -a foreign content and the form embodied by native linguistic means. Translation is a synthesis of two structures where foreign and native are turned into fictional quality. A translator has to counterbalance the expected contradictions between the foreign content and the native language form in order not to create a sharp contrast between the place of action and the means of expressing of the translator's native language and firmly maintain this synthesis.

The solution of this problem is primarily to maintain a foreign colouring. The value of translating fiction is precisely the preservation of the foreign colouring that gives a rise to associations with the foreign environment.The basis of preserving a foreign colouring is the language which is firmly in the frames of the literary language, the transliteration of foreign realias, the functional compensation of foreign phraseology, stylistic devices, foreign intonation and rhythm, and if it does not appear in translation, the quality of translation is questionable. As Humboldt says, a translation must carry that national mind which is different, this is the formost principle of faitfulness to the original text. A translation should carry a foreign colouring, but without breaking the boundaries of moderation. If a translation is perceived as foreign, then it has achieved its highest goal.

Based on the contrasting analysis of Nikos Kazantzakis's novel "Zorba the Greek " and its Georgian translation, we tried to find out how the translator adequately understands the nuances of the original ethnical consciousness, which is one of the characteristics of the Kazantzakis's style 
and how to translate them properly. Nikos Kazantzakis's language is always interesting for researchers and provides them with various material. The writer's special approach to language is evident in all his writings. As noted above, in addition to the abundance of his native Cretan dialect, the writer uses his own fictional neologisms in his novels, which complicate the process of translator's work. Mentality of ethno-linguistic specifics is clearly shown in such examples as dialectisms and neologisms. It is important to take realies and background knowledge into account in order to understand ethnic consciousness and mentality properly and to translate it further. In this article we will try to analyze the extent to which the translator takes all of these components into account to obtain an adequate translation. A linguist Akbar, in discussing translation, points out that a good translator must be familiar with the culture, customs, and social status of the community that language he/she translates from. This will rather rise the quality of translation (Akbari, 2013: 13). The stylistic relevance or inadequacy of the original text and its translation is not analytically fixed in a reader's mind. The stylistic adequacy of the original and the translation will become apparent to the reader only then, when he / she will be able to choose the linguistic portraits of the author and characters in the translation, if in his/her consciousness an aristocrat and common, illiterate and educated people talk the same way, if a reader has a feeling that he / she has read a genuinely fictional text in his / her own language, accompanied by a foreign scent (Panjikidze, 1980). A famous translator Eugene A.Nida in the article "For the Art of Translation", lays out the characteristics that a good translation is generally required:

1."The translator must perceive or understand the words of the original texts, both literally and stylistically."

2. „, "He/she must overcome the difference between the two linguistic structures.

3. " "In his/her translation he/she has to re-create the stylistic structure of the original" (Nida, 2013: 140). We can conclude that in our case, the translator meets all three criteria only partially. She may well understand the language of the original, but there are occasions when she makes a gross mistake which shows that she does not have the background knowledge which is necessary for translating of a lexical unit which expresses a particular realia. Realias represent the objects of material culture and events, ethno-national peculiarities, customs and the words expressing of the historical facts (and also firm linguistic word combinations, which contain such words) which don't have any equivalents in other cultures in most cases and signify notions and objects connected with the concepts of 
culture, historical epoch, social and state systems. Accordingly, translation of realias is a part of the problem of expressing national, historical features and colouring. The notion "realia" itself refers to an object or notion that is materially existing or has already existed. As a rule, they are the objects of material culture which are characteristic for any people, nations or society and express national identity and colouring. As it has been already noted, there are many different classifications of realias from which we consider a broad-based interpretation of this notionand includes: geographical, ethnographical, social and political realies. It is a well-known fact that before a translator starts translating, he/she must comprehend the place of realia, its contextual meaning, in what form and mode the author gives it, and in what stylistic ways the author uses in order to introduce its semanitic and conotative meanings to a reader. The author of the work of fiction introduces a realia as a fact of foreign reality for the bearers of a given language.There are the following ways of delivering realies:

\section{1. a) Transliteration; b) Transcription}

Transcription and transliteration includes translating the relevant realies into the text with the help of graphic units of the language of translation, as close as possible to the original phonetic means of the language of translation. The words of the source language is expressed by the graphic form of the target language. Translators often use transcription, though its usage is depended on the the addressee of the text. A translator must pay attention to how much this realia is well known for readers,e.g. the words PR (Public relations) or a lobbyist. These notions are understandable for young readers in general and they don't almost cause any misunderstanding, but if they are used in such press which readers may be old people, the translator must think definitely to use transcription or not in this case and change them with more neutral notions, e.g. social relations, forcing groups and etc.

\section{2. a) Calque}

Calquing gives an opportunity to express realia with the help of maximal maintaining of its semantic. Although, maintaining of semantic does not mean to save colouring because transmition of a part of the word is possible by using a target language. The method of calquing is used during proverbs translation when due to different reasons it is necessary to maintain both their meaning and the basixs of their meaning.

b) Semi-calquing

Semi-calquing is a mean of partly loaning of words, when a word consists of the elements of partly target language and partly the source one.

c) „Assimilation”; 
d) Semantic neologisms;

3. An approximate translation (a way of conveying equivalent of vocabulary), when a unit is found which in spite of its no coincidence to the initial realia, carries a semantic similarity to it and explains a reader the essence of the event to be described in order to signify a foreign realia.

4. A contextual translation-this method in essence resembles approximate translation and is opposed to lexical translation, since when using this method, the translation a word may have an equivalent that differs from the definition in the dictionary. In this case, a context is the main thing for a translator. This method itself includes replacing the lexical equivalence with the contextual one, logically related equivalence during translation. The disadvantage of such translation is a complete omission of realia as a national colouring (Barkhudarov, 1975: 96).

5. Hyponymic Translation - This method of translation of the realies implies a general notion of a specific term in the translation of realies and is mainly used to express unfamiliar realies for readers;

6. Replacing of source language realia with a realia of the target language;

7. Expressing a foreign realia for both languages;

8. Omission of realias;

In the process of translating realias, the choice of any realias is directly related to the task of the translator: to maintain the linguistic unit colouring at the expense of possible semantics, or to express the meaning of realias at the expense of colouring limitation?

Let us examine the relevance of these ways of expressing realias based on empirical material, since the viability of any theoretical construct is determined by its ability to solve practical tasks. At the same time, the specifics of the fictional text itself and the authorial intent are of the utmost importance.

As an author, Kazantzakis's aim is to introduce the realias related to the Cretan world to his readers. But the translator applies different methods of translating realias, in the selection of which subjective factors are of particular importance. Due to the politcultural character of the text, the process of translating realias is complicated by the specific interplay between Cretan and other Greek islands and the need to reflect these interactions on Georgian ground. However, it must be said that the technology of translating realias is universal and differs from specific linguistic material. Naturally, not only the author's intent but also the position of the translatorpractitioner plays a major role in choosing this method, which relies on the 
translator's knowledge and experience gained in the working process and often acts without using of theoretical guidance.

As we have already noted, it is important to have background knowledge in the process of translation. Background knowledge is a part of mass culture and is well known for different communities. Background knowledge is important for understanding of the meaning of the texts with different topics and functional-stylistics. Most scientist agree that studying of texts is only from the linguistic point of view is unjustified, since the meaning of separate expressions and the text do not consist only of the sum of the meanings of its constituent elements. The opinion is formed in different ways while translating which includes the factors of linguistic and extralinguistic knowledge to be taken into account. Background knowledge plays an important role in extralinguistic knowledge. Background knowledge is a cognitive category and is one of the types of extralinguistic knowledge. It represents a nation's social-cultural background which is more or less reflected in their languages. It is precisely the part of the culture that must be studied with the full and in-depth understanding of the original texts in order to fully transmit these values through the language of translation. In Western literature the term extralinguistic knowledge is used, and the term "background knowledge" is used in Russian scientific literature. According to E.Vereshagin and V.Kostomarov's definitions, background knowledge is the knowledge of a speaker or a listener which is implied in the communication process. This knowledge represents the basics of linguistic relations. Verbalisation of background knowledge does not take place in every day relations. Background knowledge can be discussed as "the common knowledge of the participants of the communication act" which provides mutual understanding during talking (Vereshagin, Kostomarov, 1990:126). In I.Shein's opinion, background knowledge includes different types of knowledge that influences on communication process, our expectation and presupposition and represents a part of communication situation. Background knowledge can be considered as "a ready formula"offered by the cultural-linguistic group toits members. It is usual that these "ready opinions" which are in the frames of one culture, is changed according to social status, private experience and different factors. (Sheina, 2009: 111).

It is important for a writer

1. Historical-cultural background (information on how the country, its society and culture developed in the historical process). Texts often contain hints and allusions to historical personalities and literary characters. In order for the translator to introduce this to the reader, he/she needs 
special erudition. K. Hart identifies the following public areas that contain background information:

1. Cultural-the behavior and culture of people, specific groups are represented.

2. Economical-related to management and business management.

3. Material walth or business management.

4. Genda-includes culture, behavior and psychology between a man and a woman.

5. Historical-introdicing historical facts, how they impact and how they are interpreted.

6. Interdisciplinary - explanation of theory, concept, idea and methodology borrowed from other discipline.

7. Philosophical - to clarify the nature and phenomenon.

8. Physical and Spatial - reflects how space affects and how a person perceives it.

9. Political - the environment that affects the public goals and agendas.

10. Social - the environment where work is created and done,how people will accept and interpret it.

Background knowledge is various. V. Vinogradov differs three types of nackground knowledge:

1. General, e.g. Achilles Hill

2. Regional and country studies background knowledge.

3. Background knowledge is social-cultural information which is peculiar for a concrete nations, accepted by its population and is reflected on this nation's group language. It is principally important that this is not only the information about the animals existing in this particular region or recipes of their nationaldishes. Although, it is a part of background knowledge also. Background knowledge is the knowledge, that exists only in one language, in its lexis and word combinations (Vinogradov, 2001:36).

Thus, background knowledge is one of the important competencies of a translatos. Background knowledge includes the information about the culture of both source and target languages and their common erudition in synchronic and diachronic aspects.

In I. Ignatev's opinion, one of the reasons of an unsuccessful translation is improper background knowledge. This may be due to inadequate knowledge of political life, socio-political realias, and the current situation in the world. Thus we can conclude that a competent translator of fiction should possess extra-linguistic knowledge. In any language, the system of linguistic meanings reflects the practical experience of the human 
being, both external and internal, that is, the practical experience of a collective speaking one particular language. If the experience of collectives speaking different languages is the same, the meanings that are expressed in these languages are the same. The greatest difficulty in translation arises when the situation described in the source language text does not exist in the experience of the collective of the target language, in other words, when socalled "realias" are described in the source language text (Barkhudarov, 1975:94).

In translating, thought is formed in various ways, in which it is necessary to consider the factor of linguistic and extralinguistic knowledge. Background knowledge plays an important role in extralinguistic knowledge. Background knowledge is a cognitive category and one of the types of extralinguistic knowledge. It represents social-cultural background of a nation which more or less is reflected in the language. This is precisely the part of the culture that must be studied with the full and in-depth understanding of the original text in order to fully transmit these values through the language of translation. In Western literature the term extralinguistic knowledge is used, and the term "background knowledge" is used in Russian scientific literature. Observing the empirical material we have chosen, it turned out that the author of the translation of Nikos Kazantzakis's novel "Zorba the Greek", does not have a necessary background knowledge for translating of specific realities and lexical elements adequately. As part of the translation of dialecticisms into the Kazantzakis language, the translator upholds the basic requirement of translation theory that dialecticisms should not be replaced by dialecticisms and that they should be translated into a literary language. Although in this case the peculiarity of the writer's manners of narration and the elements expressing the richness of his language, as well as the factors characteristic of geographical realias are lost, the translator has no other choice but to translate the context by substituting the literal language of dialecticism. In the ethnolinguistic context, which includes the culture, customs and nation's mentality in the language, the translator cannot transmit these specific ethnolinguistic nuances in translation because she lacks the background knowledge required to perform a perfect translation. One notable example is the Turkish-language neologism yox < Turkish yok (no, nothing) that is included in the daily speech of the Greeks, especially for the lower classes, with the use of similar neologism in their speech. Kazantzakis's characters often use this neologism from the Turkish language. This word is not unfamiliar for Georgians as well. It came to Georgia from the speech of Azarbaijanian population Turkish people living in neighborhood. Thus, the 
translator was able to transmit this lexical element invariably in the

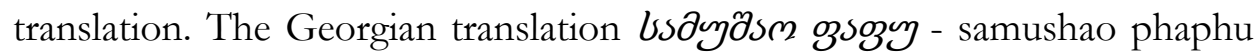
(the work has been winded up) (Kazantzakisi, N, 2018: 13) of the original

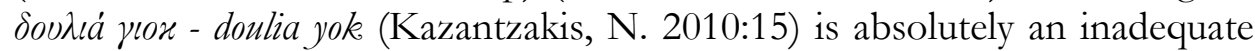
translation. The realia where this sentence must be said is not taken into account. In this case, the lack of background knowledge clearly indicates that Turkish words were frequently used on Crete and in Greece, in general, as Turkish language influenced the local spoken language through historical relations and Turkish lexical units became carriers of certain colourings.

\section{Conclusion}

Nikos Kazantzakis's writing language combines both poetry and prose, his language is as bold and brave as a true Cretan is. It is difficult for translators to express the diversity of his language and brightness of his word. Only a reader of the original text can enjoy Kazantzakis's pearls of his language, celebration of a new life of the forgettable words and expressing of his love towards native Cretan dialect. We have nothing to say about the author's neologisms, which pleasantly completes the reader the process of reading and forces to penetrate deeper into his word, to find its meaning, and eventually to digest it. Unfortunately, in Kazantzakis's translated works, the reader seems to be supplied with an adapted version of the ready-made Kazanakis language, where the magic and the color of the writer's language are lost and only the sense remains, that the writer wants to introduce to his readers, in spite of these all, it is a great pleasure to understand the thoughts of this great writer. All translators of Kazantzakis's writings have a great deal of courage and willpower, as they started themselves such a difficult and responsible job which is called translating of Kazantzakis's books.

\section{Acknowledgements}

This work was supported by Shota Rustaveli National Science Foundation (SRNSF) PHDF-18-1253, Project Title: 'Translation peculiarities of neologisms and dialectisms according to the Georgian translations of Nikos Kazantzakis's novels".

\section{References}

Akbari, M. (2013). The Role of Culture in Translation. Journal of Academic and Applied Cabré, M.T. (1999) Terminology. Theory, Methods and Applications. Benjamins, Amsterdam, Philadelphia. 
Bien, P. (1962). Nikos Kazantzakis, New York: Columbia University Press.

Kazantzakis, N. (2010). Zorba the Greek Kazantraki Nikou, [Vios kai politeia tou Alexi Zorba], Athina.

Kazantzakis, N. (2018). Zorba the Greek Kazantzakisi, N., [Alexis Zorbas tskhovreba] "Diogene", Tbilisi.

Nida, E. (2013). On Translation Nida, E. [Targmanis khelovnebistvis] Tsignidan „Tvalsatsieri“, Tbilisi:,Petiti“.

Panjikidze, D. (1999). Panjikidze D. [kartuli Targmanis istoriis Sakitkhebi]. Tbilisi., TSU

Panjikidze, D. (1988). Theory and Practice of Translation. Panjikidze D., [targmnis teoria da praktika]. Tbilisi. , TSU

Panjikidze, D. (1980). Letters Panjikidze, D. [Tserilebi]. Tbilisi: „Merani“

Barkhudarov L.S., (1975). Language and Translation Problems of general and specific theory of translation [ iazik i perevod. Voprosi obshei i chastnoi teorii perevoda]. M.: Mejdunarodnie Otnoshenie

Sheina, I. (2009). Role of background knowledge in written discurse comprehension [Rol fonovikh znanii $v$ panimanii inoiazichnogo teksta] Vestnik Pomorskogo Universiteta.

Vereshagin, E. M., Kostomarov, V. G. (1990). The leanguage and the culture [Iaziki i kultura]. Moskva.

Vinogradov, V. S. (1996). The Leanguage of newspaper [Iazik gazeti v aspekte]. Moskva.

Fedorov, A.V. (1983). The Art of Translation and the Life of Literature: Essays. Fedorov A.V. [Iskustva perevoda i jizn literaturi] L. 